\title{
A pyruvate decarboxylase-mediated therapeutic strategy for mimicking yeast metabolism in cancer cells
}

Bronwyn Scott ${ }^{l}$, Jianliang Shen ${ }^{l}$, Sara Nizzero ${ }^{1,2}$, Kathryn Boom $^{l}$, Stefano Persano ${ }^{l}, Y$ Mi $^{l}$,

5 Xuewu Liu ${ }^{1}$, Yuliang Zhao ${ }^{3,4}$, Elvin Blanco ${ }^{1}$, Haifa Shen ${ }^{1,5}$, Mauro Ferrari ${ }^{1,6, *}$, Joy Wolfram ${ }^{1,3, *}$

${ }^{1}$ Department of Nanomedicine, Houston Methodist Research Institute, Houston, TX 77030, USA.

${ }^{2}$ Applied Physics Graduate Program, Rice University, Houston, TX 77005, USA.

$10{ }^{3}$ CAS Key Laboratory for Biomedical Effects of Nanomaterials \& Nanosafety, National Center for Nanoscience \& Technology of China, University of Chinese Academy of Sciences, Beijing 100190, China.

${ }^{4}$ Institute of High Energy Physics, Chinese Academy of Sciences, Beijing 100049, China.

${ }^{5}$ Department of Cell and Developmental Biology, Weill Cornell Medicine, New York, NY 10065,

15 USA.

${ }^{6}$ Department of Medicine, Weill Cornell Medicine, Weill Cornell Medicine, New York, NY 10065, USA.

$20{ }^{*}$ Corresponding authors. Tel.: +1 7134418439 (M.F.), +1 7134418939 (J.W); fax: +1 713441 3655 .

Email addresses: mferrari@houstonmethodist.org (M.F), jvwolfram@houstonmethodist.org (J.W)

(C) 2016. This manuscript version is made available under the Elsevier user license http://www.elsevier.com/open-access/userlicense/1.0/ 


\section{Graphical Abstract}

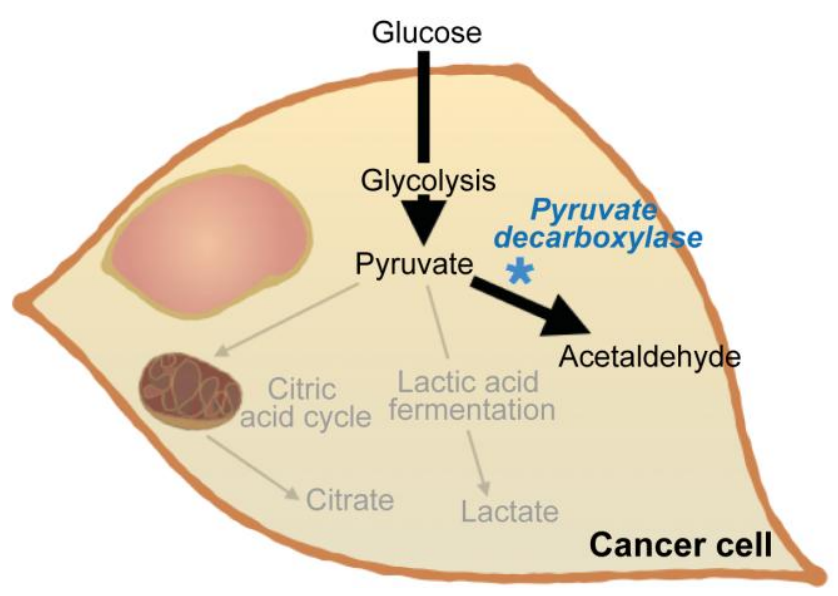

30 Abstract

Cancer cells have high rates of glycolysis and lactic acid fermentation in order to fuel accelerated rates of cell division (Warburg effect). Here, we present a strategy for merging cancer and yeast metabolism to remove pyruvate, a key intermediate of cancer cell metabolism, and produce the toxic compound acetaldehyde. This approach was achieved by administering the yeast enzyme

35 pyruvate decarboxylase to triple negative breast cancer cells. To overcome the challenges of protein delivery, a nanoparticle-based system consisting of cationic lipids and porous silicon was employed to obtain efficient intracellular uptake. The results demonstrate that the enzyme therapy decreases cancer cell viability through production of acetaldehyde and reduction of lactic acid fermentation.

40

Keywords: Cancer metabolism, multistage vector, nanotechnology, pyruvate decarboxylase, Warburg effect 


\section{Introduction}

Approximately half a million people are annually expected to die of cancer in the United States, making this disease the second leading cause of death [1]. Although cancer is an umbrella term for over one hundred diseases, there exist common characteristics shared by all cancers,

50 often referred to as the hallmarks of cancer [2,3]. These hallmarks include self-sustained growth, evasion of apoptosis, unlimited replication, invasion, angiogenesis, abnormal metabolism, evasion of the immune system, genomic instability, and inflammation. Many strategies have been employed to target these hallmarks, including cytotoxic drugs, natural compounds, hormonal therapies, antibodies, oncolytic viruses, immune system modulators, photothermal therapies, and

55 small interfering RNA (siRNA) [4-16]. The majority of these cancer therapeutics aims to halt cancer progression by initiating programmed cell death or preventing cell division. The major challenge in developing therapeutics lies in finding ways to specifically target cancer cells without detrimentally affecting normal cells. Moreover, the prevalence of drug resistance necessitates the development of new therapeutics and strategies so that patients may continue to

60 receive efficacious therapies [4]. A promising but less commonly used strategy for suppressing cancer growth involves targeting abnormal metabolic pathways.

Here, we have devised a strategy for merging metabolic pathways in cancer and yeast cells for therapeutic purposes. Namely, the yeast enzyme pyruvate decarboxylase has been used to interfere with cancer cell metabolism through the consumption of pyruvate and the production

65 of acetaldehyde (Figure 1), a reaction that does not typically occur in mammals [17]. Pyruvate is the substrate for both the citric acid cycle (aerobic metabolism) and lactic acid fermentation (anaerobic metabolism). These respiratory pathways are essential for cell survival as they produce energy in the form of adenosine triphosphate (ATP) and precursors for biomolecules utilized to generate new cells [18]. Despite lower energy yields, cancer cells have been shown to favor high

70 rates of lactic acid fermentation even in the presence of oxygen [19]. This phenomenon, termed the Warburg effect, is thought to occur because cancer cells are less dependent on efficient energy 
production than the generation of biological precursors that can serve as building blocks for new cells [20]. In fact, the process of converting pyruvate to lactate produces a supply of intermediate metabolites, which can be used to construct lipids, nucleic acids, and proteins that are essential

75 materials for cells. The Warburg effect also entails higher levels of glycolysis, resulting in increased production of the glycolytic metabolite pyruvate [20,21]. Since pyruvate decarboxylase specifically targets pyruvate, which is produced in high amounts in cancer cells, the resulting therapeutic effects are likely to be more pronounced in malignant cells. In addition to suppressing lactic acid fermentation, the conversion of pyruvate to acetaldehyde could also have detrimental

80 effects on cancer cells due to the toxic effects of acetaldehyde, which include increased membrane permeability and reduced cell viability [22]. In particular, exposure to acetaldehyde has been shown to cause polymerization of microtubules, lipid peroxidation, collagen production, and adverse mitochondrial effects [23].

Pyruvate decarboxylase has not been used in cancer treatment since 1966 when it was

85 proven to successfully inhibit tumor cell glycolysis by competitive enzyme inhibition, resulting in significant reduction of tumor growth [24]. Despite the study's promising results, it is likely that the therapeutic effects were drastically limited as the authors lacked strategies for intracellular delivery of the enzyme into cancer cells. Notably, the cellular internalization of therapeutic peptides and proteins is an area of great interest in drug delivery research today [25]. Moreover,

90 even if proteins are able to enter the cells through receptor-mediated endocytosis, entry through endosomal uptake usually concludes with enzymatic degradation in the lysosome [26]. Protein delivery is now possible with current technologies, and studies have demonstrated varying success with liposomal vehicles [27, 28] and cell-penetrating peptides [29-31]. In fact, nanomedicine has shown great promise in recent years and several nanodrugs have received

95 clinical approval, including various liposomal and polymer-based carriers [32, 33]. Nanoparticles offer an approach to overcome transport obstacles in the body, consequently increasing therapeutic efficacy and reducing side effects. In particular, multistage delivery platforms that 
have several components are well-equipped to navigate biological barriers [34-36].

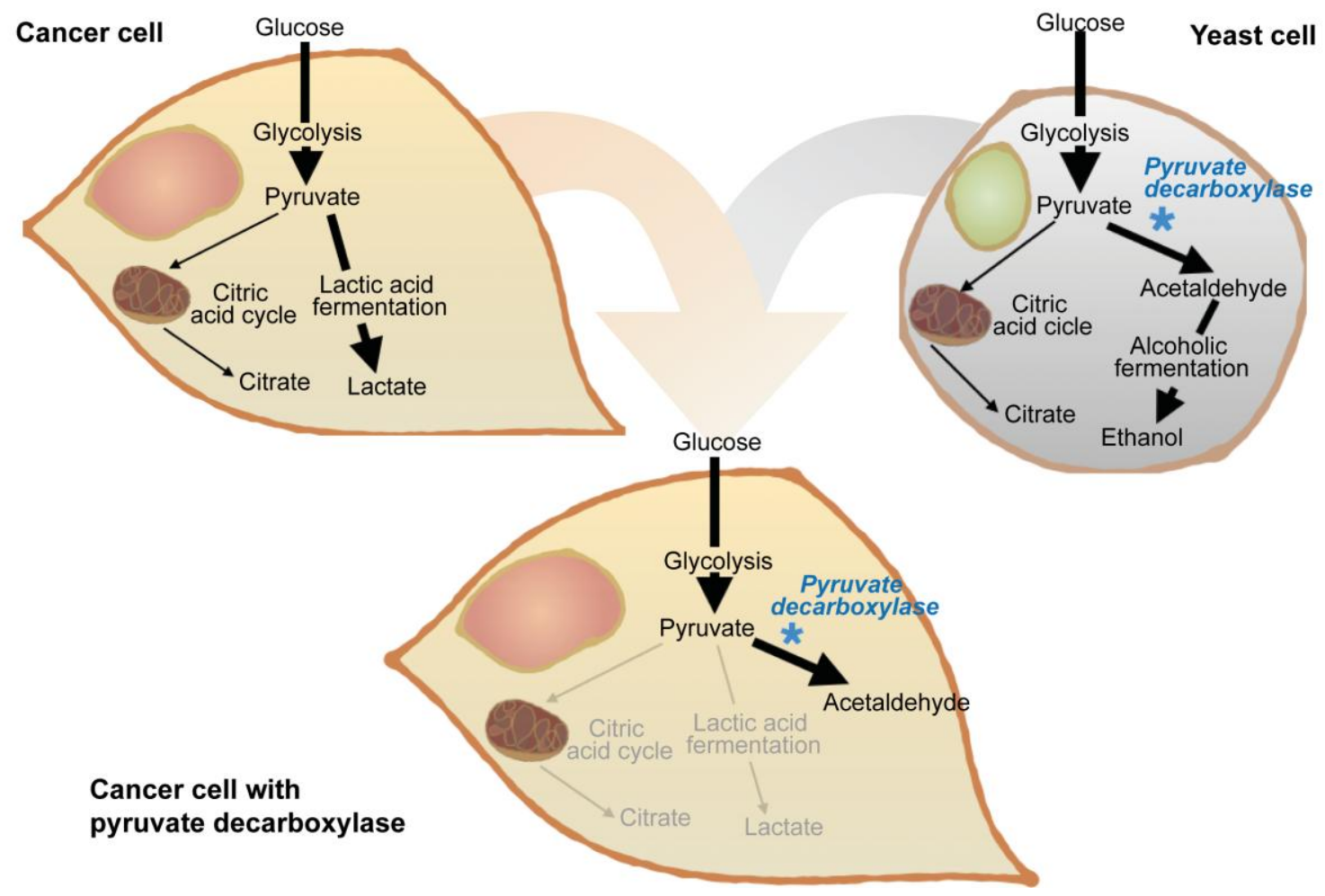

Figure 1. Schematic representation of select metabolic pathways in cancer cells and yeast cells. The figure demonstrates how the enzyme pyruvate decarboxylase can be used to converge cancer and yeast metabolic pathways. The exposure of cancer cells to this enzyme prevents pyruvate 105 from efficiently being utilized for lactic acid fermentation. In addition, pyruvate decarboxylase produces the toxic compound acetaldehyde. This therapeutic strategy aims to reduce cancer cell viability through a dual approach: the suppression of critical metabolic pathways and the generation of a toxic substance.

In this study, the commercial cationic lipid-based protein delivery vehicle PULSin was used in combination with a multistage vector (MSV) system to facilitate cellular internalization of pyruvate decarboxylase. PULSin works by forming a protein-lipid complex that can enter cells 
through endocytosis and then escape from the lysosome into the cytosol [37]. PULSin consists of the cationic lipid dioctadecylamido-glycylspermine (DOGS) [37]. Since DOGS and other cationic

115 lipids frequently display charge-induced toxicity [38], PULSin was assembled with the MSV delivery system to increase biocompatibility. The MSV is a porous silicon-based microparticle that can be loaded with a wide variety of nanoparticles [39-48]. Cell culture studies have shown that MSV particles are internalized through endocytosis [39, 49-51]. Additionally, multiple animal studies have demonstrated that the MSV carrier is non-toxic [39, 52-55]. Previously, we

120 have also demonstrated that the MSV can eliminate the toxicity of positively-charged polymeric nanoparticles [39]. In addition to increasing the safety of nanotherapeutics, the MSV protects the cargo from degradation, preferentially binds to tumor vasculature, and enables sustained release of cargo [35]. Previous studies investigating the degradation of the MSV have demonstrated that the particles disintegrate within $48 \mathrm{~h}$, leading to the gradual release of cargo [56-59]. In particular,

125 studies have shown that the MSVs degrade faster in cell culture media (24 h) than in saline (48 h) [57]. Taken together, these characteristics make the MSV carrier an ideal candidate for protein delivery.

\section{Materials and methods}

\subsection{Materials}

Materials were acquired from the following sources: penicillin-streptomycin solution, MPER mammalian protein extraction reagent, phosphate buffered saline (PBS; Hyclone), and fetal bovine serum (FBS; Hyclone) from Thermo Fisher Scientific; Dulbecco's modified Eagle's Medium (DMEM; 4 mM L-glutamine, $4.5 \mathrm{~g} / \mathrm{L}$ glucose, sodium pyruvate; Hyclone) from GE

135 Healthcare Life Sciences; PULSin protein delivery kit (with R-phycoerythrin and HEPES buffer) from Polyplus-transfection; pyruvate decarboxylase from baker's yeast (S. cerevisiae) from Sigma Aldrich; MDA-MB-468 and MDA-MB-231 human breast cancer cells from ATCC; Llactate assay kit (colorimetric) and aldehyde quantification assay kit (colorimetric) from Abcam; 
CellTiter 96 AQueous non-radioactive cell proliferation assay from Promega.

\subsection{Particle assembly and characterization}

A PULSin/protein complex was formed according to the manufacturer's instruction. Briefly, pyruvate decarboxylase or R-phycoerythrin were diluted in $20 \mathrm{mM}$ Hepes buffer at a concentration of $15 \mu \mathrm{g} / \mathrm{ml}$ and mixed with PULSin at a concentration of $4 \mu \mathrm{l} / \mu \mathrm{g}$ protein. The PULSin/protein complex was separated from free protein through centrifugation $(21,100 \times \mathrm{g}, 1$

$145 \mathrm{~h}$ ). The supernatant was analyzed with dynamic light scattering (DLS) to ensure that the PULSin/protein complex was pelleted. The protein encapsulation efficiency was determined by measuring the fluorescence intensity of R-phycoerythrin in the supernatant using a Synergy H4 Hybrid microplate reader (BioTek, Ex $488 \mathrm{~nm} / \mathrm{Em} 575 \mathrm{~nm}$ ). The size of pyruvate decarboxylase, PULSin, and PULSin/pyruvate decarboxylase in HEPES buffer was measured with DLS using a Zetasizer Nano ZS (ZEN 3600) from Malvern Instruments.

MSV particles were fabricated using electrochemical etching and photolitography as previously reported [60]. The particles were oxidized in a $30 \%$ solution of hydrogen peroxide at $95{ }^{\circ} \mathrm{C}$ for $2 \mathrm{~h}$, washed, and counted following previously established protocols [41]. Scanning electron microscopy (SEM) images of the MSVs were obtained as previously described [57]. For 155 MSV loading, the PULSin/protein complex was mixed with MSV particles $\left(7 \times 10^{4}-1.06 \times 10^{6}\right.$ MSV particles/ $\mu \mathrm{g}$ protein) using a benchtop shaker (750 rpm, $30 \mathrm{~min}$, room temperature). The MSV particle/PULSin/protein complex was separated from free PULSin and protein through centrifugation $(900 \times \mathrm{g}, 3 \mathrm{~min})$. The supernatant was analyzed with DLS to ensure that the PULSin/protein complex remained in the supernatant, while the MSV particle/PULSin/protein

160 complex was pelleted. The PULSin loading efficiency in the MSV was determined by measuring the fluorescence intensity of R-phycoerythrin (Ex $488 \mathrm{~nm} / \mathrm{Em} 575 \mathrm{~nm}$ ) in the supernatant as described above and accounting for the protein encapsulation efficiency in PULSin. For further studies, a ratio of $1.3 \times 10^{5} \mathrm{MSV}$ particles/ $\mu \mathrm{g}$ protein was used. The zeta potential of pyruvate decarboxylase, PULSin, PULSin/pyruvate decarboxylase, MSV particles, MSV particle/PULSin, 
165 and MSV particle/PULSin/pyruvate decarboxylase in distilled water was measured by laser doppler microelectrophoresis (Smoluchowski's theory) using a Zetasizer Nano ZS (ZEN 3600).

\subsection{Cell culture}

MDA-MB-231 and MDA-MB-468 cells were cultured in DMEM supplemented with $10 \%$ fetal bovine serum, 100 units $/ \mathrm{mL}$ penicillin, and $100 \mu \mathrm{g} / \mathrm{mL}$ streptomycin. Cells were 170 maintained in a humidified incubator at $37^{\circ} \mathrm{C}$ and $5 \% \mathrm{CO}_{2}$.

\subsection{Cellular uptake efficiency}

Protein delivery with the PULSin protein delivery kit was performed as per manufacturer's directions. MDA-MB-468 cells were seeded overnight in 96-well plates at a density of $4 \times 10^{3}$ cells/well. The cells were exposed to PULSin $(1.2 \mu \mathrm{l} /$ well $)$ or PULSin/R-

175 phycoerythrin $(0.3 \mu \mathrm{g}$ protein/1.2 $\mu \mathrm{l}$ PULSin/well) in serum-free media for $4 \mathrm{~h}$, after which the media was replaced with complete growth media. The fluorescence intensity of the cells was measured after $24 \mathrm{~h}$ and $72 \mathrm{~h}$ using a Synergy H4 Hybrid microplate reader (BioTek, Ex 488 $\mathrm{nm} / \mathrm{Em} 575 \mathrm{~nm})$. For studies of R-phycoerythrin uptake and MSV particle/PULSin/Rphycoerythrin uptake, MDA-MB-468 cells were seeded as described above and particles were

180 added to complete media and incubated with cells for $24 \mathrm{~h}, 48 \mathrm{~h}$, or $72 \mathrm{~h}(0.3 \mu \mathrm{g}$ protein/well). The fluorescence intensity was measured as described above. The cellular uptake of Rphycoerythrin delivered with the MSV/PULSin complex was also visualized in live cells using an Eclipse Ti inverted fluorescence microscope (Nikon).

\subsection{Cell viability studies}

MDA-MB-468 cells were seeded in 96-well plates overnight at a density of $4 \times 10^{3}$ cells/well. The cells were exposed to PULSin $(1.2 \mu \mathrm{l} / \mathrm{well})$, pyruvate decarboxylase $(0.3 \mu \mathrm{g} / \mathrm{well})$, or PULSin/pyruvate decarboxylase $(0.3 \mu \mathrm{g}$ protein/1.2 $\mu \mathrm{l}$ PULSin/well) in serum-free media for 4 $\mathrm{h}$, after which the media was replaced with complete media. Cell viability was measured with the CellTiter 96AQueous non-radioactive cell proliferation assay according to the manufacturer's

190 instructions. Absorbance was measured with a Synergy H4 Hybrid microplate reader (BioTek, $\lambda$ 
$=490 \mathrm{~nm}$ ). Results were normalized to control cells. For studies of cell viability upon exposure to MSV particle/PULSin, MDA-MB-468 and MDA-MB-231 cells were seeded as described above. The cells were then treated with MSV particles $\left(5.6 \times 10^{4}\right.$ particles/well), PULSin $(1.2 \mu 1 /$ well $)$, or MSV particles/PULSin $\left(1.2 \mu \mathrm{l}\right.$ PULSin/5.6 $\times 10^{4}$ particles/well $)$ for $24 \mathrm{~h}, 48 \mathrm{~h}$, or $72 \mathrm{~h}$. MDA-

195 MB-468 cells were also exposed to MSV particles/PULSin/pyruvate decarboxylase $(0.3 \mu \mathrm{g}$ protein/well). Cell viability was measured as described above.

\subsection{Measurements of lactate and acetaldehyde}

For measurements of lactate concentration, MDA-MB-468 cells were seeded overnight in 96-well plates at a density of $6.6 \times 10^{3}$ cells/well. The cells were exposed to PULSin (1.2

$200 \mu \mathrm{l} /$ well $)$, pyruvate decarboxylase $(0.3 \mu \mathrm{g} /$ well $)$, or PULSin/pyruvate decarboxylase $(0.3 \mu \mathrm{g}$ protein/1.2 $\mu \mathrm{l}$ PULSin/well) in serum-free media for $4 \mathrm{~h}$, after which the media was replaced with media containing $1 \%$ FBS. After 24 , the cell culture media was analyzed using the colorimetric L-lactate assay kit according to the manufacturer's instructions. The absorbance was read with a Synergy H4 Hybrid microplate reader (BioTek, $\lambda=450 \mathrm{~nm}$ ). For measurements of acetaldehyde

205 concentration, cells were seeded and treated as described above. Following treatment, the media was replaced with complete media. After $24 \mathrm{~h}$, cells were lysed with the M-PER mammalian protein extraction reagent and the lysates were analyzed using the colorimetric aldehyde quantification assay kit according to the manufacturer's instructions. The absorbance of the lysates was measured at various time points using a Synergy H4 Hybrid microplate reader $210 \quad$ (BioTek, $\lambda=405 \mathrm{~nm}$ ).

\subsection{Statistical analysis}

$T$-test comparisons (two-tailed, unpaired) were conducted to evaluate statistical significance between two groups.

\section{3. Results and discussion}

\subsection{PULSin assembly and characterization}


A crucial determinant of the success of pyruvate decarboxylase therapy is successful delivery of this enzyme. Notably, protein delivery is usually challenging due to the size and instability of these biomolecules [25]. Enzymes are especially vulnerable, since minor alterations

220 in protein structure can lead to loss of activity. PULSin was selected as a delivery vehicle, since this lipid formulation has previously been shown to form a complex with proteins without affecting protein activity [37]. Moreover, while most protein delivery strategies require complex conjugation procedures, a protein-PULSin complex can be formed with a simple mixing step. Additionally, PULSin has been shown to permit cellular internalization and endosomal escape of 225 proteins [37]. In this study, pyruvate decarboxylase was complexed with PULSin in order to enable intracellular delivery. The size and zeta potential of the free enzyme, PULSin, and the PULSin/enzyme complex were measured with DLS and laser doppler microelectrophoresis. The results reveal that PULSin nanoparticles $(64 \pm 14 \mathrm{~nm})$ undergo a slight increase in size upon forming a complex with the enzyme $(70 \pm 28 \mathrm{~nm}$ ) (Figure 2A). Moreover, the zeta potential of 230 PULSin decreases from $+53.2 \mathrm{mV}( \pm 0.8 \mathrm{mV})$ to $+27.2 \mathrm{mV}( \pm 0.5 \mathrm{mV})$ after protein complexation (Figure 2B). Analysis of the protein encapsulation efficiency demonstrated that 70.7\% of the added protein amount was complexed with the PULSin carrier (Figure 2C). The corresponding loading capacity was $8.8 \%$ 

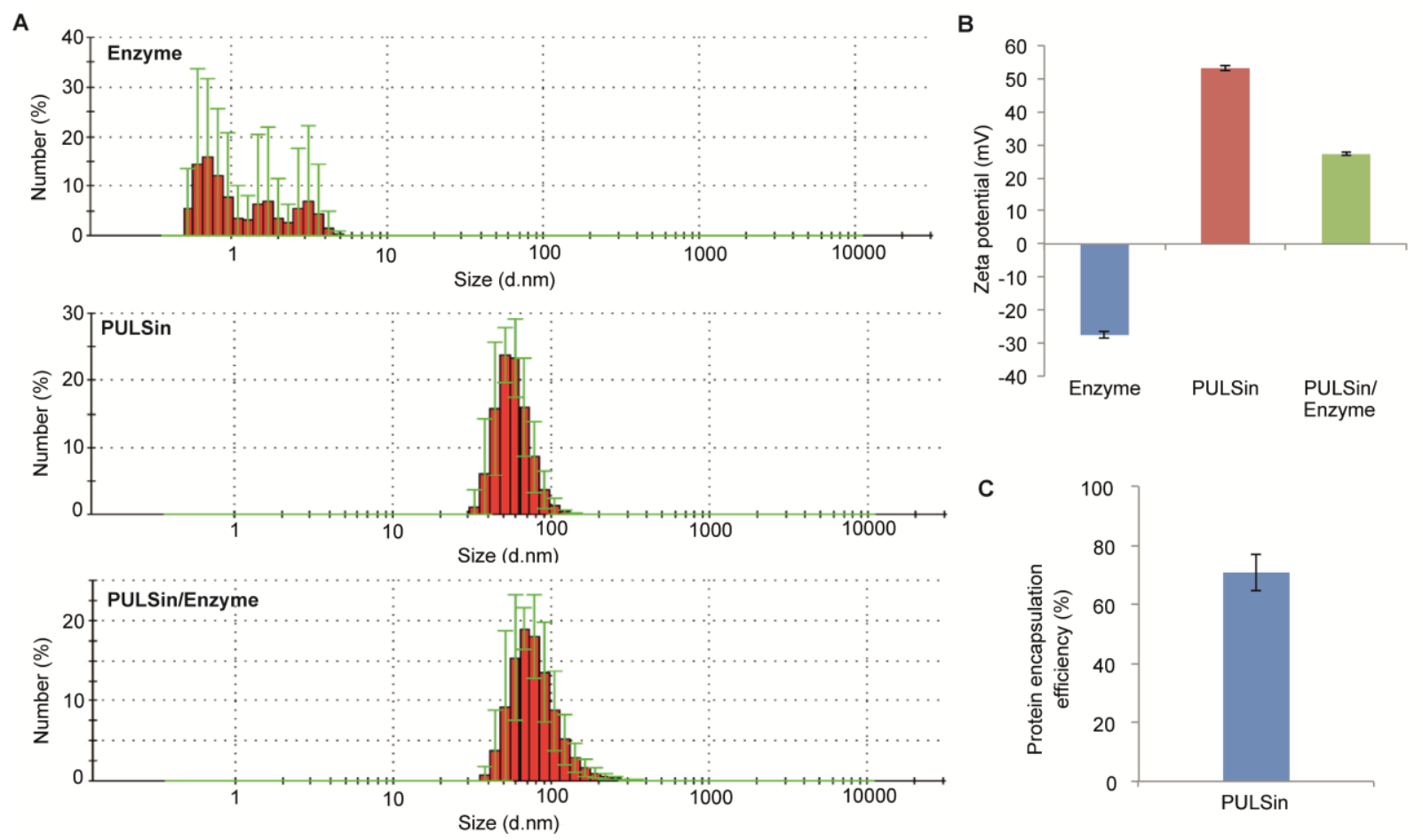

Figure 2. Characterization of the enzyme delivery system. A) The size of the enzyme (pyruvate decarboxylase), PULSin, and the PULSin/enzyme complex were determined using dynamic light scattering. Data is presented as mean \pm s.d. of five measurements (10 runs each). B) The zeta

240 potential was measured with laser doppler micro-electrophoresis. Data is presented as mean \pm s.d. of five measurements (10 runs each). C) Protein encapsulation efficiency was determined utilizing the fluorescent protein R-phycoerythrin. Data is presented as mean \pm s.d. of triplicates.

\subsection{Enzyme delivery}

The treatment strategy of merging cancer and yeast metabolism is particularly well suited for triple-negative breast cancer (TNBC), since this type of cancer displays increased levels of glucose uptake [61, 62] and glycolysis [63], the metabolic pathway that converts glucose to pyruvate. Moreover, the treatment options for TNBC are limited and the disease usually has worse outcomes compared to other types of breast cancer, necessitating the development of new therapeutic strategies [64]. Here, the anticancer effect of pyruvate decarboxylase therapy was 
assessed in the TNBC cell line MDA-MB-468, since this cell line was previously reported to have the highest rates of glucose consumption and lactate production in a panel of six breast cancer cell lines [65]. To assess the cellular uptake efficiency of the PULSin complex, the fluorescent protein R-phycoerythrin was used as a model protein. The results indicate that intracellular protein

255 delivery in MDA-MB-468 cells was effective using the PULSin transfection method. In particular, the fluorescence intensity of cells exposed to the PULSin/protein complex was significantly higher than the background fluorescence of cells (Figure 3A).

\subsection{Anticancer effects of pyruvate decarboxylase}

Upon confirming that the PULSin carrier could be used to deliver proteins to MDA-MB-

260468 cells, a cell viability assay was performed to assess the anticancer activity of pyruvate decarboxylase. The results demonstrate that the enzyme caused an $\sim 80 \%$ reduction in cell viability after $72 \mathrm{~h}$, while no statistically significant difference between control cells and treated cells could be seen after $24 \mathrm{~h}$ (Figure 3B). Notably, cells treated with the free enzyme, did not display any loss of viability at $24 \mathrm{~h}$ or $72 \mathrm{~h}$, indicating that intracellular delivery of the protein is

265 necessary for therapeutic activity (Figure 3B). To confirm that enzyme activity was maintained following intracellular delivery the levels of acetaldehyde, the product in the enzyme reaction, was measured in protein lysates of cells exposed to the PULSin/pyruvate decarboxylase complex. Since the enzyme caused the majority of cells to undergo cell death in response to treatment after $72 \mathrm{~h}$, the levels of acetaldehyde were measured after $24 \mathrm{~h}$. Analysis of lysates from cells treated

270 with PUSLin/pyruvate decarboxylase showed that the levels of acetaldehyde increased for $44 \mathrm{~h}$, after which a plateau was observed, potentially due to depletion of pyruvate (Figure 3C). In fact, no detectable levels of acetaldehyde could be observed in the samples during the first $4 \mathrm{~h}$ of analysis, indicating that the production of acetaldehyde was initiated after cell lysis when samples were brought to room temperature. Therefore, it is plausible that cells use efflux pumps to rapidly

275 expel acetaldehyde, a phenomenon that has previously been proposed to take place in yeast cells [66]. These results provide evidence that complexation with PULSin and exposure to an 
intracellular environment does not impair enzyme function.

Moreover, since glycolysis-derived pyruvate is primarily diverted to lactate fermentation in cancer cells, the levels of lactate in MDA-MB-468 cells were measured. Exposure to the

280 PULSin/pyruvate decarboxylase complex caused the lactate levels in the cell culture media to decrease from $0.82 \mathrm{mM}$ to $0.5 \mathrm{mM}$ after $24 \mathrm{~h}$ (Figure 3D). Interestingly, the free enzyme also caused a slight decrease in lactate levels (Figure 3D), which could be due to depletion of pyruvate from the cell culture media.

A

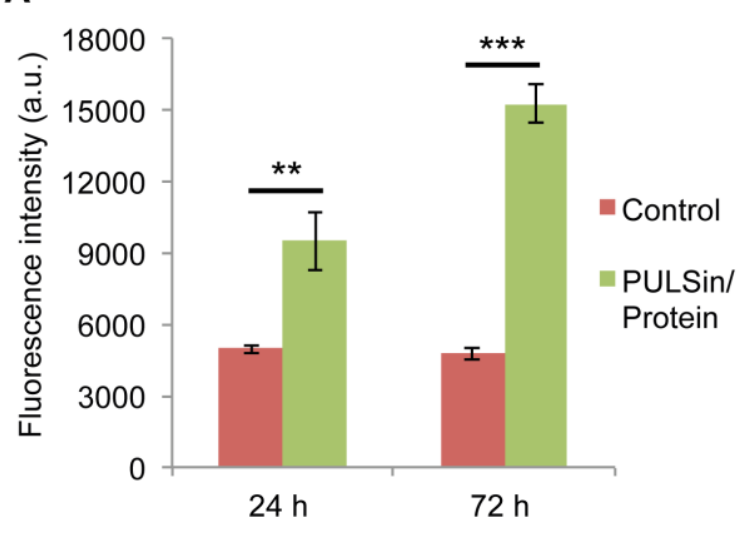

\section{C}

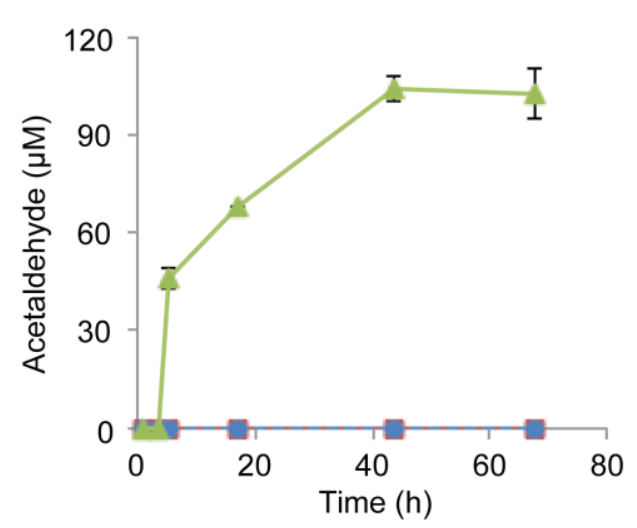

B

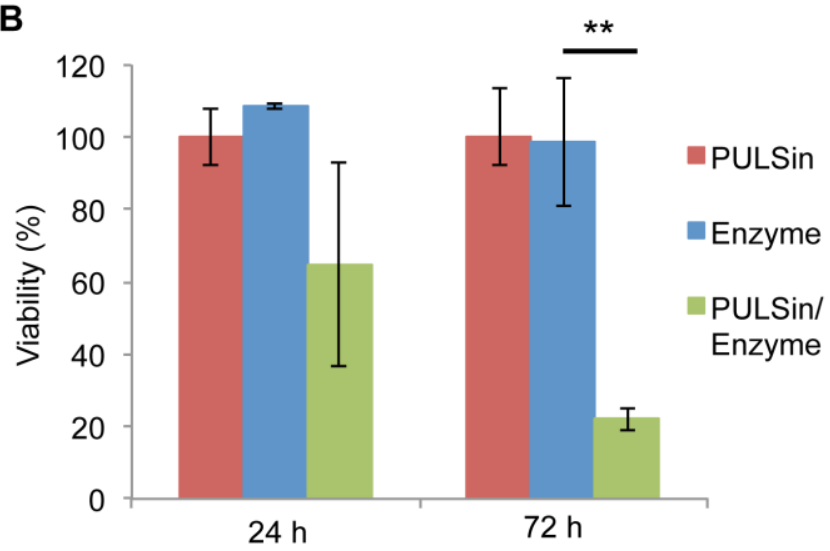

D

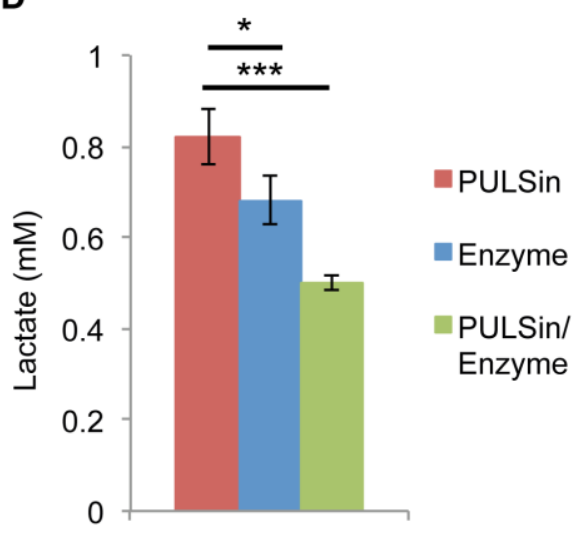

Figure 3. Biological effects of the PULSin/pyruvate decarboxylase complex in MDA-MB-468 breast cancer cells. A) Cellular uptake of PULSin/protein (R-phycoerythrin). Untreated cells were used as a control. B) Cell viability after $24 \mathrm{~h}$ and $72 \mathrm{~h}$. Values were normalized to those of cells exposed to PULSin. C) Measurements of acetaldehyde concentration in cell culture lysates after 
$29024 \mathrm{~h}$. Time points represent the reaction time after initiating the assay. D) Measurements of lactate concentration in cell culture media after $24 \mathrm{~h}$. Data is presented as mean \pm s.d. of triplicates. $* * P<0.01 ; * * * P<0.001$.

\subsection{MSV delivery}

295 The MSV platform has previously been used for the delivery of liposomes [44, 47, 52, 53, 67, 68], micelles [69], and various polymeric nanoparticles [39, 41, 54, 70]. Here, the PULSin/pyruvate decarboxylase complex was assembled with the MSV in order to facilitate delivery. SEM revealed that the discoidal MSV had a diameter of $1 \mu \mathrm{m}$ and a height of $400 \mathrm{~nm}$ (Figure 4A). The zeta potential of the oxidized MSV, the MSV/PULSin complex, and the MSV/PULSin/enzyme complex were $-22.5 \mathrm{mV}( \pm 5.6 \mathrm{mV}),+35.6 \mathrm{mV}( \pm 2.4 \mathrm{mV})$, and +20.8 $\mathrm{mV}( \pm 0.6 \mathrm{mV})$, respectively (Figure 4B). The PULSin loading efficiency in the MSV was assessed at various MSV particle/ $\mu \mathrm{g}$ protein ratios. At $7 \times 10^{4}$ particles $/ \mu \mathrm{g}$ protein the PULSin loading efficiency was $46.6 \%$ (Figure 4C). Upon increasing the particle amount to $1.3 \times 10^{5}$, the loading efficiency increased to $70.4 \%$ (Figure 4C). Further increasing the number of particles resulted in marginal improvements in loading efficiency. Therefore, a ratio of $1.3 \times 10^{5} \mathrm{MSV}$ particles $/ \mu \mathrm{g}$ protein was used for experimental studies. It is worth noting that the reported increase in loading efficiency does not indicate that the amount of encapsulated PULSin in a single particle increases. 

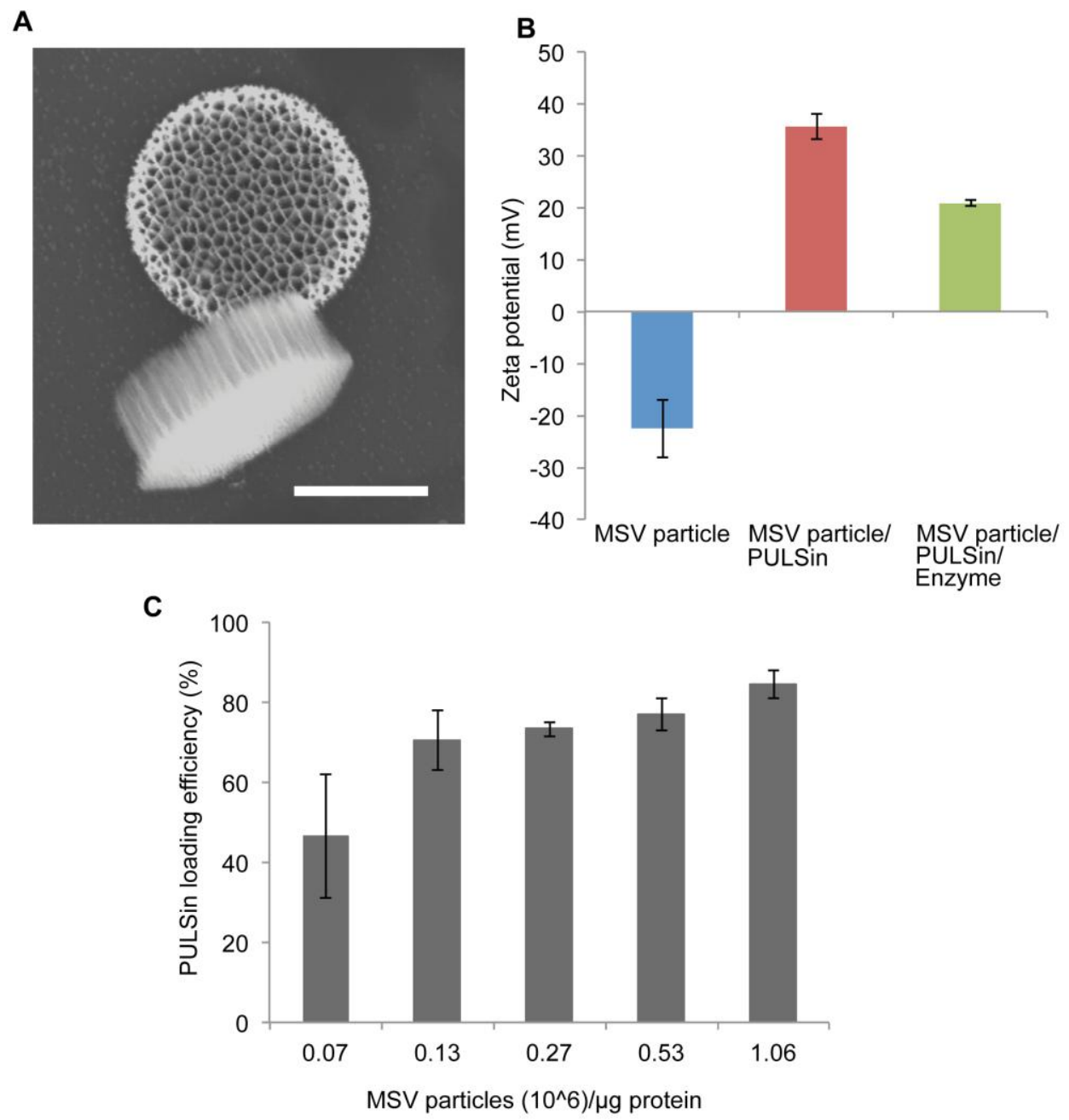

310 Figure 4. Characterization of the multistage vector (MSV) particle/PULSin/enzyme system. A) Scanning electron microscopy image of the MSV particle. Scale bar, $500 \mathrm{~nm}$. B) Zeta potential measurements of the MSV particle, MSV particle/PULSin, MSV particle/PULSin/enzyme. Data is presented as mean \pm s.d. of five measurements (10 runs each). C) PULSin loading efficiency inside MSV particles. Data is presented as mean \pm s.d. of triplicates.

Since cationic particles frequently display toxicity, the effects of the empty PULSin carrier on MDA-MB-468 cells were assessed. The results demonstrate that PULSin did not reduce cell viability following a $24 \mathrm{~h}, 48 \mathrm{~h}$, or $72 \mathrm{~h}$ incubation period (Figure $5 \mathrm{~A}$ ), suggesting that the anticancer effects observed with the PULSin/puruvate decrboxylase complex were solely due 
320 to enzyme activity. As responses to nanoparticles often vary among cell lines [71], the potential toxicity of the PULSin carrier was also evaluated in MDA-MB-231 human breast cancer cells. On the contrary to the MDA-MB-468 cells, MDA-MB-231 cells displayed a 40\% reduction in cell viability in response to PULSin (Figure 5B). Notably, one of the many benefits of the MSV delivery system, is its capability to reduce the toxicity of cationic nanoparticles, as previously

325 demonstrated [39]. Here, we evaluated whether MSV loading could lower the toxicity of PULSin in MDA-MB-231 cells. Indeed, the results demonstrate that the MSV completely eliminated the toxicity of PULSin after $24 \mathrm{~h}$ and $48 \mathrm{~h}$, while toxicity was reduced after $72 \mathrm{~h}$ (Figure 5B). To confirm that the MSV-mediated improvement in cell viability was not a result of lower levels of PULSin uptake, the cellular internalization of the fluorescent control protein R-phycoerythrin was

330 assessed. Accordingly, levels of protein uptake were similar upon delivery with PULSin or MSV/PULSin (Figure 5C). It is worth noting that since these uptake studies were performed in complete media, protein internalization was substantially lower than that observed in serum-free media (Figure 3A).

Next, the uptake levels of free protein and protein delivered with MSV/PULSin were 335 measured in MDA-MB-468 cells. While the free enzyme displayed low levels of cellular internalization, MSV delivery substantially increased protein uptake (Figure 5D). Furthermore, fluorescent microscopy confirmed that the protein accumulated inside cells as a result of MSV/PULSin delivery (Figure 5D). Moreover, MSV/PULSin delivery of puruvate decarboxylase caused a $\sim 30 \%$ and $\sim 50 \%$ reduction in cell viability after $48 \mathrm{~h}$ and $72 \mathrm{~h}$, respectively (Figure 5E).

340 This observation suggests that enzyme function is maintained following MSV delivery. 

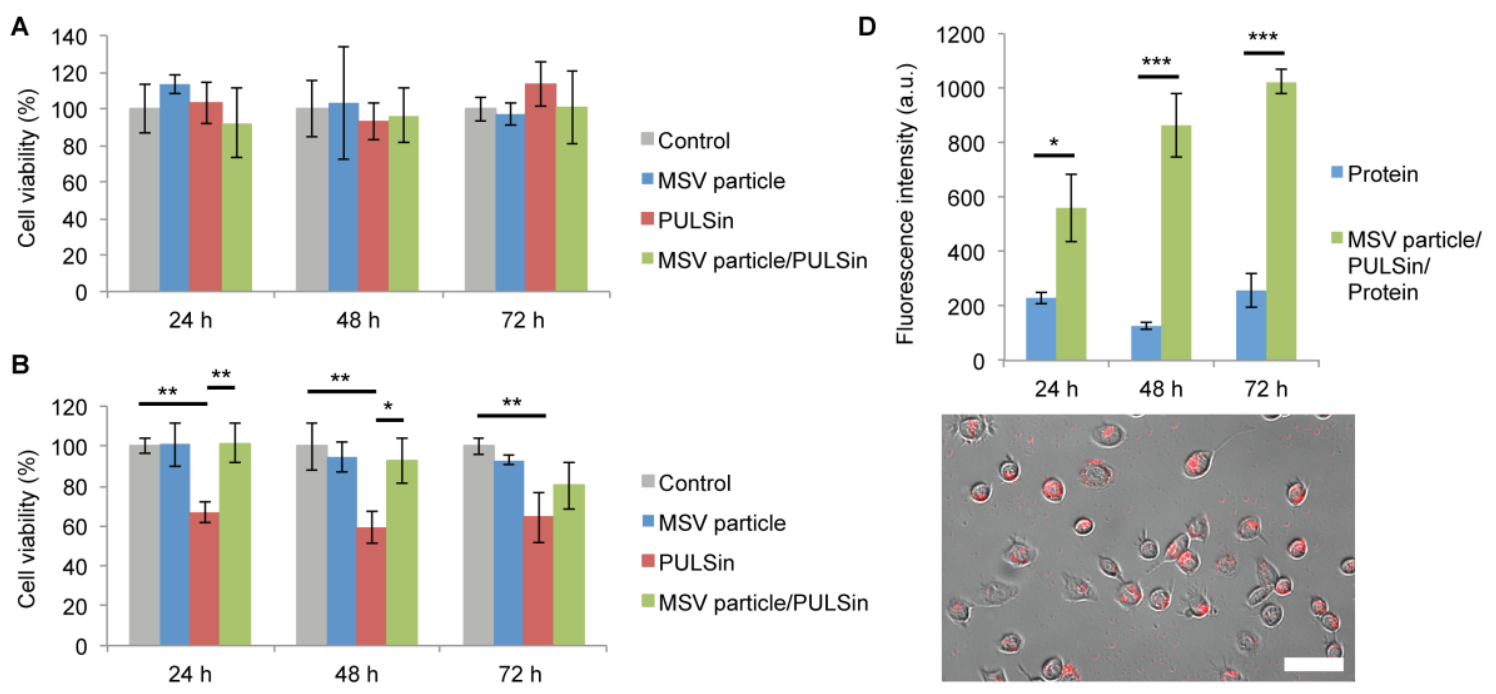

C

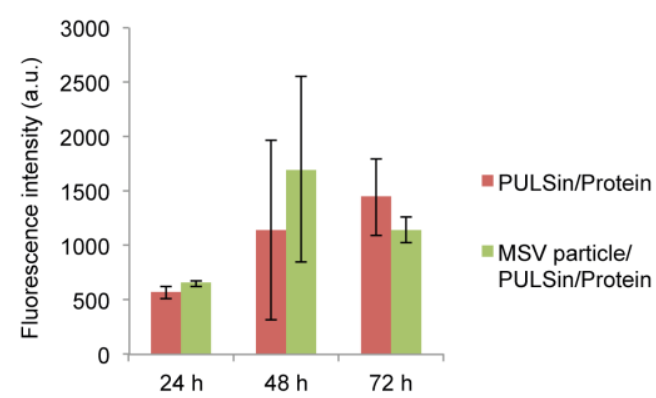

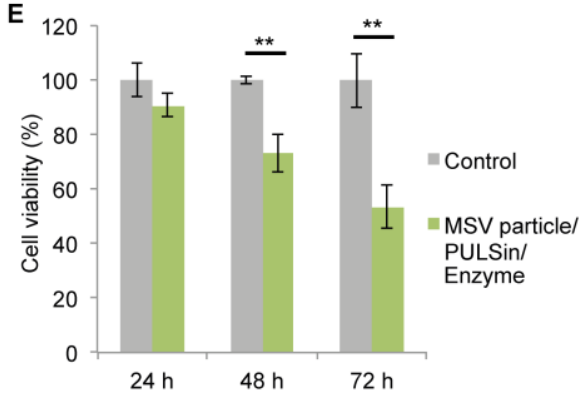

Figure 5. Biological effects of the MSV particle/PULSin/enzyme platform. A,B) Cell viability in response to the MSV particles, PUSLin, and the MSV particle/PULSin complex in MDA-MB468 cells (A) and MDA-MB-231 cells (B). C) Uptake of PULSin/protein (R-phycoeythrin) and

345 MSV particle/PULSin/protein (R-phycoeythrin) in MDA-MB-231 cells. Fluorescence intensity was normalized to that of control cells. D) Uptake of protein (R-phycoeythrin) and MSV particle/PULSin/protein (R-phycoeythrin) in MDA-MB-468 cells. Fluorescence intensity was normalized to that of control cells. Representative image of R-phycoerythrin uptake was captured with a fluorescent microscope following MSV/PULSin delivery. Scale bar, $50 \mu \mathrm{m}$. C) Cell

350 viability in response to the MSV particle/PULSin/enzyme platform in MDA-MB-468 cells. Data is presented as mean \pm s.d. of triplicates. ${ }^{*} P<0.05 ; * * P<0.01 ; * * * P<0.001$.

\section{Conclusion}

The majority of cancer drugs are designed to prevent replicative processes, thus focusing 
355 on one characteristic of the hallmarks of cancer. Since cancer patients frequently experience poor outcomes due to drug resistance and toxic side effects, different strategies for suppressing tumor growth could prove highly beneficial. Indeed, therapeutic agents that target invasion, angiogenesis, abnormal metabolism, immune surveillance, genomic instability, and inflammation could provide new solutions for reducing the cancer death toll. Here, we present a novel approach

360 designed to exploit cancer metabolism. In particular, cancer cells produce increased levels of pyruvate, which is shunted into the lactic acid fermentation pathway in order to generate precursors for materials that can be used to build new cells. The proposed therapeutic strategy is to use the yeast enzyme pyruvate decarboxylase to convert pyruvate into acetaldehyde. The benefits from this approach are twofold, since the consumption of pyruvate reduces the production of biomolecules and the generation of acetaldehyde causes cancer cell death.

Notably, enzyme delivery is usually challenging, as proteins do not readily cross the cell membrane. In this study, a multistage nanodelivery platform consisting of porous silicon and cationic lipids was used to successfully obtain enzyme uptake in cancer cells. The results demonstrated that cancer cell viability was reduced in response to enzyme therapy. Measurements

370 of acetaldehyde in cell lysates confirmed that enzyme function was preserved in the intracellular environment following nanoparticle uptake. Moreover, the levels of lactate, the end product of the lactic acid fermentation pathway, were decreased in response to enzyme exposure. The initial investigations described in this study support the anticancer potential of nanoparticle-mediated delivery of pyruvate decarboxylase.

\section{Acknowledgements}

This work was funded by the Houston Methodist Research Institute. Partial funds were acquired from: the Ernest Cockrell Jr. Distinguished Endowed Chair (M.F.), the US Department of Defense (W81XWH-09-1-0212, W81XWH-12-1-0414) (M.F.), the National Institutes of 380 Health (U54CA143837, U54CA151668) (M.F.), Nylands nation Finland (J.W.), Victoriastiftelsen 
Finland (J.W.), and the Cancer Prevention Research Institute of Texas (RP121071) (M.F. and H.S.).

\section{References}

[1] Cancer Facts \& Figures 2015, in, American Cancer Society, Inc, American Cancer Society, 2015.

[2] D. Hanahan, R.A. Weinberg, The hallmarks of cancer, Cell, 100 (2000) 57-70.

[3] D. Hanahan, R.A. Weinberg, Hallmarks of cancer: the next generation, Cell, 144

390 (2011) 646-674.

[4] G. Awada, H.R. Kourie, A.H. Awada, Novel mechanisms and approaches in the medical therapy of solid cancers, Discov Med, 20 (2015) 33-41.

[5] Y. Wen, W.S. Meng, Recent In Vivo Evidences of Particle-Based Delivery of SmallInterfering RNA (siRNA) into Solid Tumors, J Pharm Innov, 9 (2014) 158-173.

395 [6] M. Zhou, J. Zhao, M. Tian, S. Song, R. Zhang, S. Gupta, D. Tan, H. Shen, M. Ferrari, C. Li, Radio-photothermal therapy mediated by a single compartment nanoplatform depletes tumor initiating cells and reduces lung metastasis in the orthotopic 4T1 breast tumor model, Nanoscale, 7 (2015) 19438-19447.

[7] J. Shen, H.C. Kim, C. Mu, E. Gentile, J. Mai, J. Wolfram, L.N. Ji, M. Ferrari, Z.W.

400 Mao, H. Shen, Multifunctional gold nanorods for siRNA gene silencing and photothermal therapy, Adv Healthc Mater, 3 (2014) 1629-1637.

[8] Y. Yang, J. Wolfram, K. Boom, X. Fang, H. Shen, M. Ferrari, Hesperetin impairs glucose uptake and inhibits proliferation of breast cancer cells, Cell Biochem. Funct., 31 (2013) 374-379.

405 [9] H. Shen, V. Mittal, M. Ferrari, J. Chang, Delivery of gene silencing agents for breast cancer therapy, Breast Cancer Res, 15 (2013) 205.

[10] H. Shen, T. Sun, M. Ferrari, Nanovector delivery of siRNA for cancer therapy, Cancer Gene Ther., 19 (2012) 367-373.

[11] C. Celia, E. Trapasso, M. Locatelli, M. Navarra, C.A. Ventura, J. Wolfram, M.

410 Carafa, V.M. Morittu, D. Britti, L. Di Marzio, D. Paolino, Anticancer activity of liposomal bergamot essential oil (BEO) on human neuroblastoma cells, Colloids Surf. B. Biointerfaces, (2013) 548-553.

[12] J. Wolfram, K. Suri, Y. Huang, R. Molinaro, C. Borsoi, B. Scott, K. Boom, D. Paolino, M. Fresta, J. Wang, M. Ferrari, C. Celia, H. Shen, Evaluation of anticancer

415 activity of celastrol liposomes in prostate cancer cells, J. Microencaps., 31 (2014) 501507.

[13] J. Wolfram, B. Scott, K. Boom, J. Shen, C. Borsoi, K. Suri, R. Grande, M. Fresta, C. Celia, Y. Zhao, H. Shen, M. Ferrari, Hesperetin liposomes for cancer therapy, Curr Drug Deliv, (2015).

420 [14] Y. Yang, J. Wolfram, X. Fang, H. Shen, M. Ferrari, Polyarginine Induces an Antitumor Immune Response through Binding to Toll-Like Receptor 4, Small, 10 (2014) 1250-1254.

[15] J. Shen, H.C. Kim, H. Su, F. Wang, J. Wolfram, D. Kirui, J. Mai, C. Mu, Z. Mao, H. Shen, Cyclodextrin and polyethylenimine functionalized mesoporous silica nanoparticles 425 for delivery of siRNA cancer therapeutics, Theranostics, 4 (2014) 487-497. 
[16] R. Molinaro, J. Wolfram, C. Federico, F. Cilurzo, L. Di Marzio, C.A. Ventura, M. Carafa, C. Celia, M. Fresta, Polyethylenimine and chitosan carriers for the delivery of RNA interference effectors, Expert opinion on drug delivery, 10 (2013) 1653-1668. [17] J. Wang, H. Dong, S. Li, H. He, Theoretical study toward understanding the catalytic 430 mechanism of pyruvate decarboxylase, J Phys Chem B, 109 (2005) 18664-18672. [18] M.G. Vander Heiden, L.C. Cantley, C.B. Thompson, Understanding the Warburg effect: the metabolic requirements of cell proliferation, Science, 324 (2009) 1029-1033. [19] W.H. Koppenol, P.L. Bounds, C.V. Dang, Otto Warburg's contributions to current concepts of cancer metabolism, Nature reviews. Cancer, 11 (2011) 325-337.

435 [20] J. Lu, M. Tan, Q. Cai, The Warburg effect in tumor progression: mitochondrial oxidative metabolism as an anti-metastasis mechanism, Cancer Lett, 356 (2015) 156-164. [21] B. Altenberg, K.O. Greulich, Genes of glycolysis are ubiquitously overexpressed in 24 cancer classes, Genomics, 84 (2004) 1014-1020.

[22] K. Henzel, C. Thorborg, M. Hofmann, G. Zimmer, U. Leuschner, Toxicity of

440 ethanol and acetaldehyde in hepatocytes treated with ursodeoxycholic or tauroursodeoxycholic acid, Biochimica et biophysica acta, 1644 (2004) 37-45.

[23] C.S. Lieber, Metabolic effects of acetaldehyde, Biochem Soc Trans, 16 (1988) 241247.

[24] A.J. Rommel, Effect of yeast pyruvate decarboxylase on Ehrlich ascites carcinoma 445 in vivo, Nature, 212 (1966) 201.

[25] V. Torchilin, Intracellular delivery of protein and peptide therapeutics, Drug Discov Today Technol, 5 (2008) e95-e103.

[26] C.M. Varga, T.J. Wickham, D.A. Lauffenburger, Receptor-mediated targeting of gene delivery vectors: insights from molecular mechanisms for improved vehicle design,

450 Biotechnol Bioeng, 70 (2000) 593-605.

[27] G.C. Reynolds, H.J. Baker, R.H. Reynolds, Enzyme replacement using liposome carriers in feline Gm1 gangliosidosis fibroblasts, Nature, 275 (1978) 754-755.

[28] P.K. Das, G.J. Murray, G.C. Zirzow, R.O. Brady, J.A. Barranger, Lectin-specific targeting of beta-glucocerebrosidase to different liver cells via glycosylated liposomes,

455 Biochem Med, 33 (1985) 124-131.

[29] S. Fawell, J. Seery, Y. Daikh, C. Moore, L.L. Chen, B. Pepinsky, J. Barsoum, Tatmediated delivery of heterologous proteins into cells, Proceedings of the National Academy of Sciences of the United States of America, 91 (1994) 664-668.

[30] S.R. Schwarze, A. Ho, A. Vocero-Akbani, S.F. Dowdy, In vivo protein transduction:

460 delivery of a biologically active protein into the mouse, Science, 285 (1999) 1569-1572. [31] G.E. Roeder, J.L. Parish, P.L. Stern, K. Gaston, Herpes simplex virus VP22-human papillomavirus E2 fusion proteins produced in mammalian or bacterial cells enter mammalian cells and induce apoptotic cell death, Biotechnol Appl Biochem, 40 (2004) 157-165.

465 [32] J.S. Rink, M.P. Plebanek, S. Tripathy, C.S. Thaxton, Update on current and potential nanoparticle cancer therapies, Curr Opin Oncol, 25 (2013) 646-651.

[33] J. Wolfram, M. Zhu, Y. Yang, J. Shen, E. Gentile, D. Paolino, M. Fresta, G. Nie, C. Chen, H. Shen, M. Ferrari, Y. Zhao, Safety of Nanoparticles in Medicine, Curr. Drug Targets, 16 (2015) 1671-1681. 
470 [34] S. Sengupta, D. Eavarone, I. Capila, G. Zhao, N. Watson, T. Kiziltepe, R.

Sasisekharan, Temporal targeting of tumour cells and neovasculature with a nanoscale delivery system, Nature, 436 (2005) 568-572.

[35] J. Wolfram, H. Shen, M. Ferrari, Multistage vector (MSV) therapeutics, J. Control. Release, 219 (2015) 406-415.

475 [36] G. von Maltzahn, J.H. Park, K.Y. Lin, N. Singh, C. Schwoppe, R. Mesters, W.E. Berdel, E. Ruoslahti, M.J. Sailor, S.N. Bhatia, Nanoparticles that communicate in vivo to amplify tumour targeting, Nature materials, 10 (2011) 545-552.

[37] A. Weiss, P. Neuberg, S. Philippot, P. Erbacher, C.O. Weill, Intracellular peptide delivery using amphiphilic lipid-based formulations, Biotechnol Bioeng, 108 (2011)

$480 \quad 2477-2487$.

[38] D.A. Balazs, W. Godbey, Liposomes for use in gene delivery, J Drug Deliv, 2011 (2011) 326497.

[39] J. Shen, R. Xu, J. Mai, H.C. Kim, X. Guo, G. Qin, Y. Yang, J. Wolfram, C. Mu, X. Xia, J. Gu, X. Liu, Z.W. Mao, M. Ferrari, H. Shen, High capacity nanoporous silicon

485 carrier for systemic delivery of gene silencing therapeutics, ACS nano, 7 (2013) 98679880.

[40] M.P. Scavo, E. Gentile, J. Wolfram, J. Gu, M. Barone, M. Evangelopoulos, J.O. Martinez, X. Liu, C. Celia, E. Tasciotti, E. Vilar, H. Shen, Multistage vector delivery of sulindac and silymarin for prevention of colon cancer, Colloids Surf. B. Biointerfaces, $490136(2015) 694-703$. [41] J. Shen, X. Wu, Y. Lee, J. Wolfram, Z. Mao, M. Ferrari, H. Shen, Porous silicon microparticles for delivery of siRNA therapeutics, J Vis Exp., 15 (2015) 52075. [42] X. Xia, J. Mai, R. Xu, J.E. Perez, M.L. Guevara, Q. Shen, C. Mu, H.Y. Tung, D.B. Corry, S.E. Evans, X. Liu, M. Ferrari, Z. Zhang, X.C. Li, R.F. Wang, H. Shen, Porous

495 silicon microparticle potentiates anti-tumor immunity by enhancing cross-presentation and inducing type I interferon response, Cell reports, 11 (2015) 957-966.

[43] H. Shen, J. You, G. Zhang, A. Ziemys, Q. Li, L. Bai, X. Deng, D.R. Erm, X. Liu, C. $\mathrm{Li}, \mathrm{M}$. Ferrari, Cooperative, nanoparticle-enabled thermal therapy of breast cancer, Advanced healthcare materials, 1 (2012) 84-89.

500 [44] H. Shen, C. Rodriguez-Aguayo, R. Xu, V. Gonzalez-Villasana, J. Mai, Y. Huang, G. Zhang, X. Guo, L. Bai, G. Qin, X. Deng, Q. Li, D.R. Erm, B. Aslan, X. Liu, J. Sakamoto, A. Chavez-Reyes, H.D. Han, A.K. Sood, M. Ferrari, G. Lopez-Berestein, Enhancing chemotherapy response with sustained EphA2 silencing using multistage vector delivery, Clin. Cancer. Res., 19 (2013) 1806-1815.

505 [45] A. Gizzatov, C. Stigliano, J.S. Ananta, R. Sethi, R. Xu, A. Guven, M. Ramirez, H. Shen, A. Sood, M. Ferrari, L.J. Wilson, X. Liu, P. Decuzzi, Geometrical confinement of Gd(DOTA) molecules within mesoporous silicon nanoconstructs for MR imaging of cancer, Cancer Lett., 352 (2014) 97-101.

[46] B. Dave, S. Granados-Principal, R. Zhu, S. Benz, S. Rabizadeh, P. Soon-Shiong,

510 K.D. Yu, Z. Shao, X. Li, M. Gilcrease, Z. Lai, Y. Chen, T.H. Huang, H. Shen, X. Liu, M. Ferrari, M. Zhan, S.T. Wong, M. Kumaraswami, V. Mittal, X. Chen, S.S. Gross, J.C. Chang, Targeting RPL39 and MLF2 reduces tumor initiation and metastasis in breast cancer by inhibiting nitric oxide synthase signaling, Proc. Natl. Acad. Sci. U. S. A., 111 (2014) 8838-8843. 
515 [47] X. Chen, D. Iliopoulos, Q. Zhang, Q. Tang, M.B. Greenblatt, M. Hatziapostolou, E. Lim, W.L. Tam, M. Ni, Y. Chen, J. Mai, H. Shen, D.Z. Hu, S. Adoro, B. Hu, M. Song, C. Tan, M.D. Landis, M. Ferrari, S.J. Shin, M. Brown, J.C. Chang, X.S. Liu, L.H. Glimcher, XBP1 promotes triple-negative breast cancer by controlling the HIF1alpha pathway, Nature, 508 (2014) 103-107.

520 [48] Y. Mi, C. Mu, J. Wolfram, Z. Deng, T.Y. Hu, X. Liu, E. Blanco, H. Shen, M. Ferrari, A Micro/Nano Composite for Combination Treatment of Melanoma Lung Metastasis, Advanced healthcare materials, (2016).

[49] R.E. Serda, J. Gu, R.C. Bhavane, X. Liu, C. Chiappini, P. Decuzzi, M. Ferrari, The association of silicon microparticles with endothelial cells in drug delivery to the

525 vasculature, Biomaterials, 30 (2009) 2440-2448.

[50] S. Ferrati, A. Mack, C. Chiappini, X. Liu, A.J. Bean, M. Ferrari, R.E. Serda, Intracellular trafficking of silicon particles and logic-embedded vectors, Nanoscale, 2 (2010) 1512-1520.

[51] J.O. Martinez, A. Parodi, X. Liu, M.G. Kolonin, M. Ferrari, E. Tasciotti, Evaluation

530 of cell function upon nanovector internalization, Small, 9 (2013) 1696-1702. [52] T. Tanaka, L.S. Mangala, P.E. Vivas-Mejia, R. Nieves-Alicea, A.P. Mann, E. Mora, H.D. Han, M.M. Shahzad, X. Liu, R. Bhavane, J. Gu, J.R. Fakhoury, C. Chiappini, C. Lu, K. Matsuo, B. Godin, R.L. Stone, A.M. Nick, G. Lopez-Berestein, A.K. Sood, M. Ferrari, Sustained small interfering RNA delivery by mesoporous silicon particles, Cancer

535 research, 70 (2010) 3687-3696.

[53] R. Xu, Y. Huang, J. Mai, G. Zhang, X. Guo, X. Xia, E.J. Koay, G. Qin, D.R. Erm, Q. $\mathrm{Li}, \mathrm{X}$. Liu, M. Ferrari, H. Shen, Multistage vectored siRNA targeting ataxiatelangiectasia mutated for breast cancer therapy, Small, 9 (2013) 1799-1808.

[54] M. Zhang, R. Xu, X. Xia, Y. Yang, J. Gu, G. Qin, X. Liu, M. Ferrari, H. Shen,

540 Polycation-functionalized nanoporous silicon particles for gene silencing on breast cancer cells, Biomaterials, 35 (2014) 423-431.

[55] T. Tanaka, B. Godin, R. Bhavane, R. Nieves-Alicea, J. Gu, X. Liu, C. Chiappini, J.R. Fakhoury, S. Amra, A. Ewing, Q. Li, I.J. Fidler, M. Ferrari, In vivo evaluation of safety of nanoporous silicon carriers following single and multiple dose intravenous

545 administrations in mice, Int. J. Pharm., 402 (2010) 190-197. [56] J.O. Martinez, C. Chiappini, A. Ziemys, A.M. Faust, M. Kojic, X. Liu, M. Ferrari, E. Tasciotti, Engineering multi-stage nanovectors for controlled degradation and tunable release kinetics, Biomaterials, 34 (2013) 8469-8477.

[57] J.O. Martinez, M. Evangelopoulos, C. Chiappini, X. Liu, M. Ferrari, E. Tasciotti,

550 Degradation and biocompatibility of multistage nanovectors in physiological systems, J. Biomed. Mater. Res. A, 102 (2014) 3540-3549.

[58] B. Godin, J. Gu, R.E. Serda, R. Bhavane, E. Tasciotti, C. Chiappini, X. Liu, T. Tanaka, P. Decuzzi, M. Ferrari, Tailoring the degradation kinetics of mesoporous silicon structures through PEGylation, J. Biomed. Mater. Res. A, 94 (2010) 1236-1243.

555 [59] B. Godin, J. Gu, R.E. Serda, S. Ferrati, X. Liu, C. Chiappini, T. Tanaka, P. Decuzzi, M. Ferrari, Multistage Mesoporous Silicon-based Nanocarriers: Biocompatibility with Immune Cells and Controlled Degradation in Physiological Fluids, Controlled release newsletter / Controlled Release Society, 25 (2008) 9-11. 
[60] B. Godin, C. Chiappini, S. Srinivasan, J.F. Alexander, K. Yokoi, M. Ferrari, P.

560 Decuzzi, X. Liu, Discoidal Porous Silicon Particles: Fabrication and Biodistribution in Breast Cancer Bearing Mice, Adv. Funct. Mater., 22 (2012) 4225-4235.

[61] S. Basu, W. Chen, J. Tchou, A. Mavi, T. Cermik, B. Czerniecki, M. Schnall, A. Alavi, Comparison of triple-negative and estrogen receptor-positive/progesterone receptor-positive/HER2-negative breast carcinoma using quantitative fluorine-18

565 fluorodeoxyglucose/positron emission tomography imaging parameters: a potentially useful method for disease characterization, Cancer, 112 (2008) 995-1000.

[62] N. Palaskas, S.M. Larson, N. Schultz, E. Komisopoulou, J. Wong, D. Rohle, C. Campos, N. Yannuzzi, J.R. Osborne, I. Linkov, E.R. Kastenhuber, R. Taschereau, S.B. Plaisier, C. Tran, A. Heguy, H. Wu, C. Sander, M.E. Phelps, C. Brennan, E. Port, J.T.

570 Huse, T.G. Graeber, I.K. Mellinghoff, 18F-fluorodeoxy-glucose positron emission tomography marks MYC-overexpressing human basal-like breast cancers, Cancer Res., 71 (2011) 5164-5174.

[63] H. Pelicano, W. Zhang, J. Liu, N. Hammoudi, J. Dai, R.H. Xu, L. Pusztai, P. Huang, Mitochondrial dysfunction in some triple-negative breast cancer cell lines: role of mTOR 575 pathway and therapeutic potential, Breast Cancer Res., 16 (2014) 434.

[64] W.D. Foulkes, I.E. Smith, J.S. Reis-Filho, Triple-negative breast cancer, N. Engl. J. Med., 363 (2010) 1938-1948.

[65] F. Morais-Santos, V. Miranda-Goncalves, S. Pinheiro, A.F. Vieira, J. Paredes, F.C. Schmitt, F. Baltazar, C. Pinheiro, Differential sensitivities to lactate transport inhibitors 580 of breast cancer cell lines, Endocr. Relat. Cancer, 21 (2014) 27-38. [66] A. Aranda, M.L. del Olmo, Exposure of Saccharomyces cerevisiae to acetaldehyde induces sulfur amino acid metabolism and polyamine transporter genes, which depend on Met4p and Haa1p transcription factors, respectively, Appl. Environ. Microbiol., 70 (2004) 1913-1922.

585 [67] J. Mai, Y. Huang, C. Mu, G. Zhang, R. Xu, X. Guo, X. Xia, D.E. Volk, G.L. Lokesh, V. Thiviyanathan, D.G. Gorenstein, X. Liu, M. Ferrari, H. Shen, Bone marrow endothelium-targeted therapeutics for metastatic breast cancer, J. Control. Release, 187 (2014) 22-29.

[68] B. Dave, S. Granados-Principal, R. Zhu, S. Benz, S. Rabizadeh, P. Soon-Shiong, 590 K.D. Yu, Z.M. Shao, X.X. Li, M. Gilcrease, Z. Lai, Y.D. Cheng, T.H.M. Huang, H.F. Shen, X.W. Liu, M. Ferrari, M. Zhan, S.T.C. Wong, M. Kumaraswami, V. Mittal, X. Chen, S.S. Gross, J.C. Chang, Targeting RPL39 and MLF2 reduces tumor initiation and metastasis in breast cancer by inhibiting nitric oxide synthase signaling, Proceedings of the National Academy of Sciences of the United States of America, 111 (2014) 8838-

5958843.

[69] J.O. Martinez, M. Evangelopoulos, R. Bhavane, S. Acciardo, F. Salvatore, X. Liu, M. Ferrari, E. Tasciotti, Multistage Nanovectors Enhance the Delivery of Free and Encapsulated Drugs, Curr. Drug Targets, (2014).

[70] E. Blanco, T. Sangai, A. Hsiao, S. Ferrati, L. Bai, X. Liu, F. Meric-Bernstam, M.

600 Ferrari, Multistage delivery of chemotherapeutic nanoparticles for breast cancer treatment, Cancer Lett., 334 (2013) 245-252.

[71] T. Xia, M. Kovochich, M. Liong, J.I. Zink, A.E. Nel, Cationic polystyrene nanosphere toxicity depends on cell-specific endocytic and mitochondrial injury pathways, ACS nano, 2 (2008) 85-96. 